\title{
The Role of Extracellular Adenosine in Regulating Mossy Fiber Synaptic Plasticity
}

\author{
Maria Kukley, ${ }^{1}$ Maximilian Schwan, ${ }^{1}$ Bertil B. Fredholm, ${ }^{2}$ and Dirk Dietrich ${ }^{1}$ \\ ${ }^{1}$ Department of Neurosurgery, University Clinic Bonn, D-53105 Bonn, Germany, and 'Department of Physiology and Pharmacology, Karolinska Institutet, \\ S-17177 Stockholm, Sweden
}

\begin{abstract}
Hippocampal mossy fiber synapses show unique molecular features and dynamic range of plasticity. A recent paper proposed that the defining features of mossy fiber synaptic plasticity are caused by a local buildup of extracellular adenosine (Moore et al., 2003). In this study, we reassessed the role of ambient adenosine in regulating mossy fiber synaptic plasticity in mouse and rat hippocampal slices. Synaptic transmission was highly sensitive to activation of presynaptic adenosine $A_{1}$ receptors $\left(A_{1} R s\right)$, which reduced transmitter release by $>75 \%$. However, most of $A_{1}$ Rs were not activated by ambient adenosine. Field potentials increased only by $20-30 \%$ when $A_{1}$ Rs were fully blocked with the $\mathrm{A}_{1} \mathrm{R}$ antagonist 8-cyclopentyl-1,3-dipropylxanthine (DPCPX) $(1 \mu \mathrm{M})$. Moreover, blocking $\mathrm{A}_{1} \mathrm{Rs}$ hardly altered paired-pulse facilitation, frequency facilitation, or posttetanic potentiation. Frequency facilitation was similar in $A_{1} R^{-/-}$mice and when measured with NMDA receptor-mediated EPSCs in CA3 pyramidal cells in the presence of DPCPX. Additional experiments suggested that the results obtained by Moore et al. (2003) can partially be explained by their usage of a submerged recording chamber and elevated divalent cation concentrations. In conclusion, a reduction of the basal release probability by ambient adenosine does not underlie presynaptic forms of plasticity at mossy fiber synapses.
\end{abstract}

Key words: CA3; granule cells; synaptic transmission; hippocampus; interface chamber; submerged chamber; high divalent cation concentration

\section{Introduction}

Short-term synaptic plasticity is regarded a very elementary correlate of learning and memory. It represents a dynamic adjustment of synaptic strength according to previous activity of the presynaptic cell, which at most lasts for a few minutes. Shortterm synaptic plasticity can be depressing or facilitating and shows a remarkable diversity between different synaptic connections (Zucker and Regehr, 2002). Hippocampal mossy fibers, connecting granule cells to CA3 pyramidal cells, display very pronounced forms of short-term synaptic enhancement (Salin et al., 1996). At this synapse, synaptic strength is temporarily augmented twofold to tenfold in response to an increase in the frequency of presynaptic activity from $<0.03$ to $100 \mathrm{~Hz}$. Because of the large unitary conductance and the very proximal dendritic location, the augmentation of a single mossy fiber synapse can fire a postsynaptic CA3 pyramidal cell (Urban et al., 2001).

These extraordinary forms of presynaptic plasticity have been a subject of intense investigation. Several properties unique to mossy fiber synapses have been found to contribute. Among those properties are presynaptic kainate receptors (Contractor et

Received 0ct. 13, 2004; revised Jan. 28, 2005; accepted Jan. 30, 2005.

This study was supported by Deutsche Forschungsgemeinschaft Sonderforschungsbereich TR3, GK 246, and DI 853/2, Swedish Science Council Grant 02553, and grants from the University Clinic Bonn (BONFOR). We are grateful to H. Beck for comments on this manuscript and to P. Stausberg for excellent technical assistance.

Correspondence should be addressed to Dr. Dirk Dietrich, Department of Neurosurgery, Experimental Neurophysiology, NCH U1 R035, University Clinic Bonn, Sigmund-Freud Straße 25, D-53105 Bonn, Germany. E-mail: dirk.dietrich@ukb.uni-bonn.de.

DOl:10.1523/JNEUROSCI.4260-04.2005

Copyright $\odot 2005$ Society for Neuroscience $\quad$ 0270-6474/05/252832-06\$15.00/0 al., 2001; Schmitz et al., 2001), release-incompetent presynaptic $\mathrm{Ca}^{2+}$ channels (Dietrich et al., 2003), presynaptic $\mathrm{Ca}^{2+}$ stores (Lauri et al., 2003), a particularly large pool of releasable vesicles (Hallermann et al., 2003), strongly inactivating presynaptic $\mathrm{K}^{+}$ channels (Geiger and Jonas, 2000), presynaptic CaM kinase II (Salin et al., 1996), and a high endogenous $\mathrm{Ca}^{2+}$ buffer content of synaptic terminals (Blatow et al., 2003).

A recent report challenged the view that mossy fiber synaptic plasticity arises from specialized intrinsic properties of the terminals and proposed that the local environment of the synapses plays a decisive role (Moore et al., 2003). It was reported that the tonic presynaptic inhibition of transmitter release by a local, high concentration of ambient adenosine is essential for the expression of paired-pulse facilitation, frequency facilitation, posttetanic potentiation, and long-term potentiation by mossy fibers. However, ambient adenosine is very sensitive to a variety of conditions such as the metabolic state of the tissue and the extracellular ion concentration (Dunwiddie and Masino, 2001; Latini and Pedata, 2001). We therefore retested the importance of ambient adenosine for mossy fiber synaptic plasticity in a recording chamber that optimizes oxygenation of the tissue and with physiological concentrations of divalent cations. Under these circumstances, we do not find evidence for a role of ambient adenosine in regulating plasticity at this synapse.

\section{Materials and Methods}

Adult C57BL/6 wild-type mice, adenosine $\mathrm{A}_{1}$ receptor $A_{1} R^{-/-}$mice (see below), or Wistar rats (postnatal days 20-60; Charles River Wiga, Sul- 
zfeld, Germany) were anesthetized with chloroform and decapitated. The brain was rapidly removed, and horizontal (mouse) or frontal (rat) hippocampal slices $(300 \mu \mathrm{m})$ were prepared (VT1000; Leica, Nussloch, Germany) in ice-cold solution containing the following (in $\mathrm{mm}$ ): 87 $\mathrm{NaCl}, 2.5 \mathrm{KCl}, 1.25 \mathrm{NaH}_{2} \mathrm{PO}_{4}, 7 \mathrm{MgCl}_{2}, 0.5 \mathrm{CaCl}_{2}, 25 \mathrm{NaH}_{2} \mathrm{CO}_{3}, 25$ glucose, and 75 sucrose $\left(95 \% \mathrm{O}_{2}-5 \% \mathrm{CO}_{2}\right)$ (Geiger and Jonas, 2000). Afterward, slices were stored for at least $45 \mathrm{~min}$ at room temperature $\left(22-24^{\circ} \mathrm{C}\right.$ ) in solution containing the following (in mM): $124 \mathrm{NaCl}, 3 \mathrm{KCl}$, $1.25 \mathrm{NaH}_{2} \mathrm{PO}_{4}, 2 \mathrm{MgCl}_{2}, 2 \mathrm{CaCl}_{2}, 26 \mathrm{NaH}_{2} \mathrm{CO}_{3}$, and 10 glucose $(95 \%$ $\mathrm{O}_{2}-5 \% \mathrm{CO}_{2}$ ). For recording, slices were transferred to either a Haas-type interface chamber or a submerged chamber and perfused $(2-3 \mathrm{ml} / \mathrm{min})$ with saline containing artificial CSF (ACSF) (in mM): $119 \mathrm{NaCl}, 2.5 \mathrm{KCl}$, $1 \mathrm{NaH}_{2} \mathrm{PO}_{4}, 1.3 \mathrm{MgCl}_{2}, 2.5 \mathrm{CaCl}_{2}, 26 \mathrm{NaH}_{2} \mathrm{CO}_{3}, 10$ glucose, and DL-2amino-5-phosphonovaleric acid $0.05\left(95 \% \mathrm{O}_{2}-5 \% \mathrm{CO}_{2}, 30^{\circ} \mathrm{C}\right)$. Slices were incubated for $45 \mathrm{~min}$ in the recording chamber before measurements were started. Extracellular recordings of field EPSPs (fEPSPs) were made using glass electrodes (4-6 M 2 ) filled with ACSF and placed under visual guidance in the stratum lucidum of the CA3 region. Monopolar stimulation was delivered through a glass electrode filled with ACSF (resistance, $\sim 1 \mathrm{M} \Omega$ ) placed in the stratum lucidum or in the granule cell layer as indicated in Results. The mossy fiber origin of fEPSPs was verified at the end of each experiment by application of the group II metabotropic glutamate receptor agonist $\left(2 S, 2^{\prime} R, 3^{\prime} R\right)-2-\left(2^{\prime}, 3^{\prime}\right.$-dicarboxycyclopropyl)glycine (DCGIV) $(1 \mu \mathrm{M})$ (Kamiya et al., 1996). The experiments were discarded if the inhibition produced by DCG-IV was $<80 \%$. Experiments were also discarded if a positive potential remained under DCG-IV with an amplitude of $\geq 10 \%$ of pre-DCG-IV level. fEPSPs were recorded with a bridge-clamp amplifier (IR-283; Neurodata Instruments, New York, NY), filtered at $3 \mathrm{kHz}$, and digitized at $20 \mathrm{kHz}$ using Igor Pro Software (WaveMetrics, Lake Oswego, OR).

Adenosine $A_{1} R^{-/-}$mice were generated as described previously (Johansson et al., 2001), backcrossed to C57BL/6Tac until genetic background was $100 \% \mathrm{C} 57 \mathrm{BL} / 6$. Wild-type and $A_{1} R^{-1-}$ mice were bred from heterozygote crossings.

Mossy fiber EPSCs were recorded as described previously (Dietrich et al., 2003). In brief, slices were kept in a submerged recording chamber and perfused with ACSF $\left(\sim 24^{\circ} \mathrm{C}\right)$. Whole-cell patch-clamp recordings (EPC7 amplifier; HEKA, Lambrecht, Germany) were obtained with the following pipette solution (in mM): $100 \mathrm{Cs}$-gluconate, $30 \mathrm{CsCl}, 5 \mathrm{QX}$ 314- $\mathrm{Br}$ [2(triethylamino)- $\mathrm{N}$-(2,6-dimethylphenyl) acetamine], 10 HEPES, 0.5 EGTA, $4 \mathrm{Na}_{2} \mathrm{ATP}$, and $4 \mathrm{MgCl}_{2}$. Mossy fibers were stimulated in the stratum lucidum, and trials were discarded if the inhibition by DCG-IV $(1 \mu \mathrm{M})$ was $<80 \%$.

In separate experiments, we tested whether the poorly water soluble, highaffinity $\mathrm{A}_{1} \mathrm{R}$ antagonist 8-cyclopentyl-1,3-dipropylxanthine (DPCPX) $\left(K_{\mathrm{D}}\right.$ $\sim 1-3 \mathrm{nM}$ ) might accumulate in the perfusion system of our recording chamber. We found that our perfusion system has to be washed for $\geq 60 \mathrm{~min}$ with $0.1 \mathrm{NaOH}$ (solvent of DPCPX) to regain the full inhibition of CA1 fEPSPs by the $\mathrm{A}_{1} \mathrm{R}$ agonist $N$-cyclopentyladenosine (CPA) [800 nM, $90-100 \%$ (see Fig. 2) (Johansson et al., 2001)]. Flushing for only 15 min reduced the CPA inhibition to $\sim 50 \%$. Before all DPCPX experiments included in this study, the system was flushed overnight (17 of 25) or for $>60 \mathrm{~min}$ ( 8 of 25).

Statistical significance of data was assessed with the two-tailed $t$ test $(\alpha=0.05)$. Data are given as mean \pm SEM.

\section{Results}

In the first series of experiments, we recorded mossy fiber fEPSPs in slices placed in an interface chamber that optimizes oxygen supply to the tissue (Tsacopoulos et al., 1981; Bingmann and Kolde, 1982). In response to paired-pulse stimulation in the stratum lucidum with an interstimulus interval of $40 \mathrm{~ms}$, fEPSPs showed strong paired-pulse facilitation $(212 \pm 12 \% ; n=5)$ (Fig. $1 A$ ), as is typical for mossy fiber synapses (Salin et al., 1996; Castillo et al., 2002; Dietrich et al., 2003). After obtaining a stable baseline of fEPSPs, the frequency of stimulation was increased from 0.033 to $1 \mathrm{~Hz}$ for $10 \mathrm{~s}$. Stimulation at $1 \mathrm{~Hz}$ induced a prominent potentiation of mossy fiber fEPSPs to $407 \pm 23 \%(n=5)$ (Fig. $1 A, B$ ) of the value obtained during $0.033 \mathrm{~Hz}$ stimulation.
This potentiation is referred to as frequency facilitation (Regehr et al., 1994; Salin et al., 1996; Toth et al., 2000; Castillo et al., 2002; Dietrich et al., 2003), and it was suggested recently that this potentiation can occur only when ambient adenosine tonically decreases transmitter release probability (Moore et al., 2003). To rapidly and fully remove the putative inhibitory effect of ambient adenosine, we applied a high concentration of the $A_{1} R$ antagonist DPCPX (Lohse et al., 1987). In striking contrast to the findings of Moore et al. (2003), $1 \mu \mathrm{M}$ DPCPX increased fEPSPs only to $128 \pm$ $16 \%(n=5)$ (Fig. $1 A)$ and did not change paired-pulse facilitation significantly (control, $212 \pm 12 \%$; DPCPX, $221 \pm 13 \%$; $n=$ 5) (Fig. 1A). Moreover, increasing stimulation frequency to $1 \mathrm{~Hz}$ in the presence of the $A_{1} R$ antagonist evoked a frequency facilitation of unchanged magnitude $(407 \pm 37 \% ; n=5)$ (Fig. $1 A, B)$. We next asked whether posttetanic potentiation might be dependent on tonic $A_{1} R$ activation. A single train of 20 pulses at $100 \mathrm{~Hz}$ induced a prominent potentiation of fEPSPs that decayed back to near-baseline levels within minutes (Fig. 1C). Five seconds after the train, fEPSPs were potentiated to $600 \pm 50 \%$ under control conditions $(n=4)$ (Fig. $1 C)$. After preapplication of $1 \mu \mathrm{M}$ DPCPX, posttetanic potentiation was nearly unchanged and amounted to $520 \pm 44 \%(n=4$; not significantly different from control conditions) (Fig. 1C).

We tested the function of presynaptic $\mathrm{A}_{1}$ Rs and the antagonistic potency of DPCPX in our preparation. As expected, perfusion of the specific $\mathrm{A}_{1} \mathrm{R}$ agonist CPA ( $800 \mathrm{nM}$ ) strongly reduced mossy fiber fEPSPs to $27 \pm 3 \%(n=3)$ (Fig. $2 A)$. Furthermore, the CPA-induced depression of fEPSPs was completely reversed during coperfusion of DPCPX ( $1 \mu \mathrm{M})$ (Fig. $2 A)$. Similar to our initial experiments (Fig. 1A), DPCPX increased fEPSPs only slightly above pre-CPA baseline levels $(118 \pm 11 \%)$ (Fig. $2 A)$.

We further verified the independence of mossy fiber synaptic plasticity of $\mathrm{A}_{1} \mathrm{R}$ activation in mice lacking the $\mathrm{A}_{1} \mathrm{R}$. In $A_{1} R^{-/-}$ mice, frequency facilitation amounted to $399 \pm 3 \%$ of baseline transmission $(n=4)$ (Fig. $2 B$ ), which is very similar to what is observed in wild-type mice (Fig. $1 B$ ), including littermates of the $A_{1} R^{-/-}$mice (data not shown). The phenotype of the mice was validated in the same slices by showing the absence of depression of Schaffer collateral-evoked CA1 fEPSPs by CPA (cf. Johansson et al., 2001) $(n=3)$ (Fig. $2 C)$.

Because the CA3 network contains many recurrent connections, fEPSPs may be contaminated by a polysynaptic component. To minimize such polysynaptic activity, we blocked AMPA, kainate, and $\mathrm{GABA}_{\mathrm{A}}$ receptors. Under these conditions, we obtained whole-cell patch-clamp recordings from CA3 pyramidal cells and recorded NMDA receptor-mediated mossy fiber EPSCs at positive holding potentials in the presence of DPCPX (Fig. 2D). When stimulation frequency was increased to $1 \mathrm{~Hz}$, EPSC $_{\text {NMDA }}$ s were potentiated to a degree very similar to that seen for fEPSPs (to $384 \pm 51 \% ; n=4$ ) (Figs. $2 D, E, 3 E$ ). Therefore, we conclude that there is an approximately fourfold increase in transmitter release from mossy fiber synapses during $1 \mathrm{~Hz}$ stimulation, which is independent of $A_{1} R$ activation.

These results are in clear contrast to findings by Moore et al. (2003). We asked whether technical differences between their study and ours can account for this discrepancy. We tested the effect of DPCPX on basal fEPSP amplitude and on frequency facilitation under various conditions to reproduce their experimental settings as close as possible: changing the stimulation site from stratum lucidum to the granule cell layer (Fig. $3 A$ ), using rat instead of mouse hippocampal slices (Fig. 3A), using a submerged recording chamber as a substitute of our interface re- 

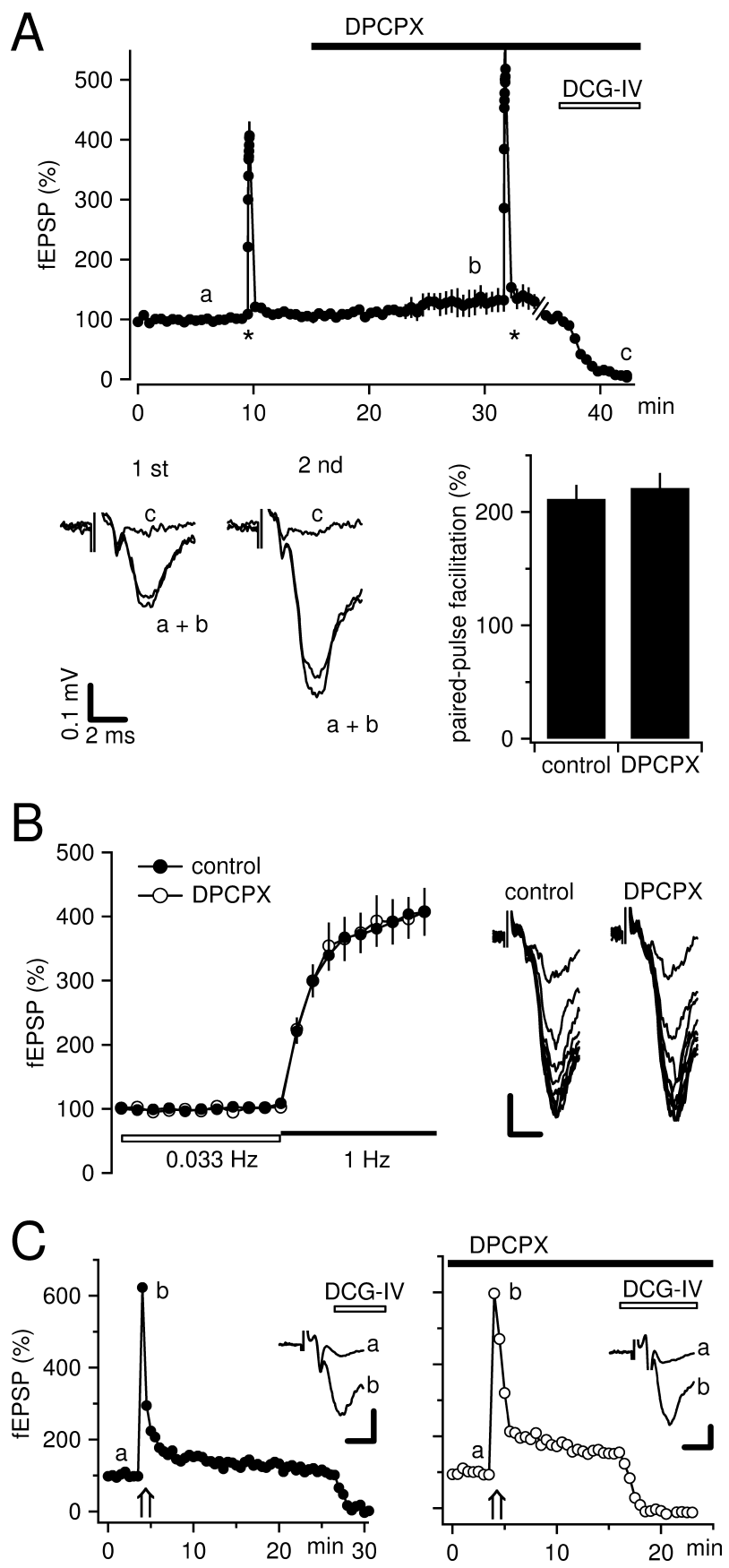

Figure 1. Antagonizing $A_{1} R s$ does not change short-term synaptic plasticity of mossy fiber synapses. $A$, Top, Time course of fEPSP amplitudes $(n=5)$. Mossy fibers were stimulated in the stratum lucidum at a rate of $0.033 \mathrm{~Hz}$. Asterisks indicate time points at which stimulation frequency was increased to $1 \mathrm{~Hz}$ for 10 stimulations. During application of the $\mathrm{A}_{1}$ RantagonistDPCPX ( $1 \mu \mathrm{m}$; black bar), fEPSPs increase only slightly (notice that the asterisks are on the same vertical position), and frequency facilitation is unchanged. At the end of each experiment, $1 \mu \mathrm{m} \mathrm{DCG-IV} \mathrm{was} \mathrm{applied} \mathrm{(white}$ bar) to verify the mossy fiber origin of stimulated fibers. Bottom, Example traces of the first and the second fEPSP (interstimulus interval of $40 \mathrm{~ms}$, average of 5 traces) taken from the time points indicated by small letters are shown on the left. A summary bar graph of the paired-pulse facilitation value calculated before and during perfusion of DPCPX is shown on the right. Blocking $A_{1}$ Rs does not alter paired-pulse facilitation. $\boldsymbol{B}$, Frequency facilitation is not dependent on $A_{1}$ Rs. Data from experiments in $A$ are replotted. Within each experiment, fEPSP amplitudes before and during DPCPXapplication were normalized on the mean amplitude of the fEPSPs preceding the change in stimulation frequency. Original example traces taken from one experiment during $1 \mathrm{~Hz}$ stimulation are shown on the right. Stimulus artifacts are blanked with white squares throughout all figures for clarity. Calibration: $0.2 \mathrm{mV}$, 2 ms. C, Posttetanic potentiation is not dependent on $A_{1}$ Rs. Left, Mossy fibers were tetanized at the time points shown by the arrow. " $\mathrm{b}$ " denotes the fEPSP amplitude measured $4 \mathrm{~s}$ after tetanus. Right, As in $\boldsymbol{B}$ but in the continuous presence of DPCPX. Calibration: $0.5 \mathrm{mV}, 2 \mathrm{~ms}$.
A
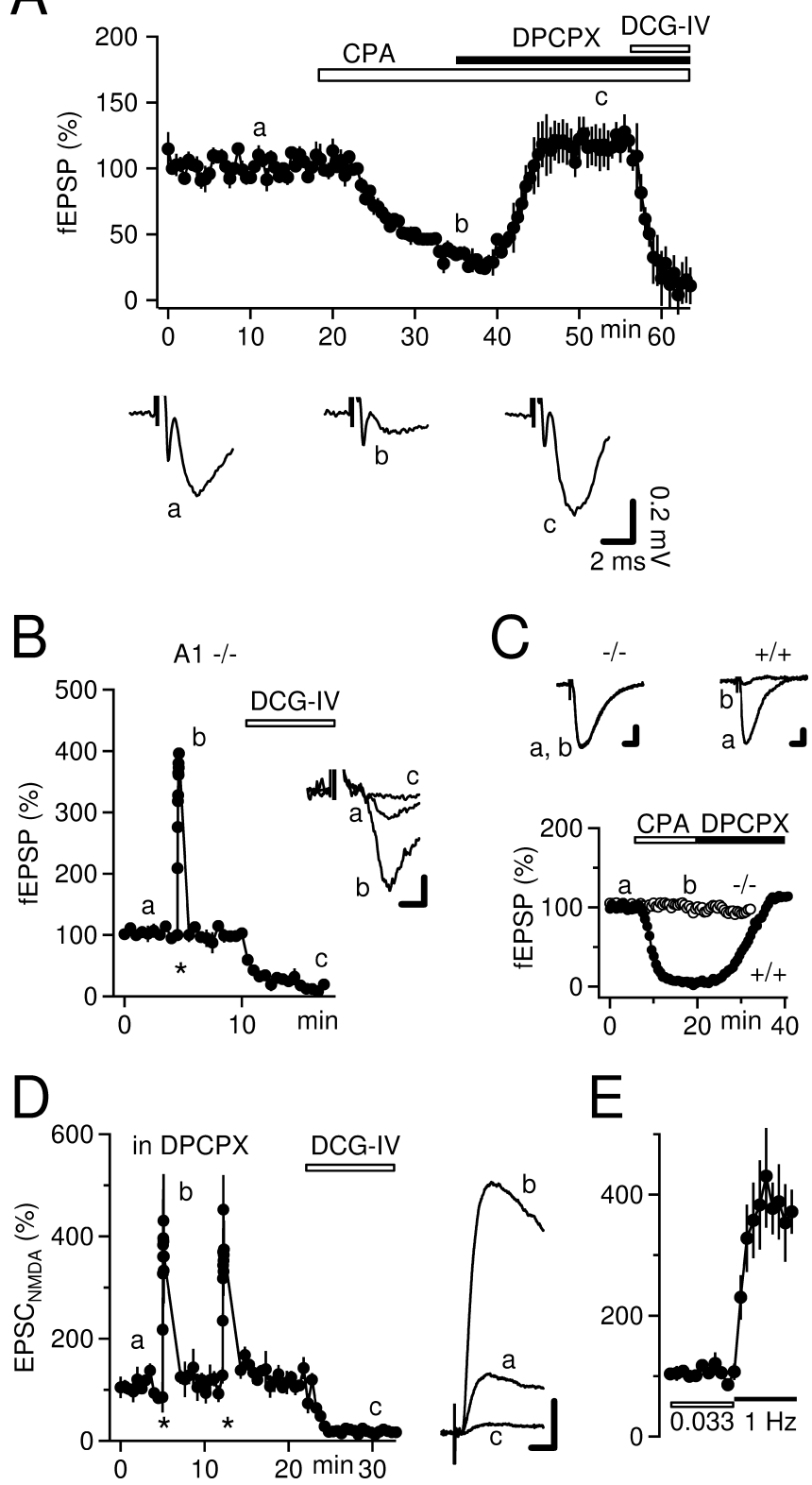

Figure 2. Frequency facilitation persists in $A_{7} R^{-/-}$mice and when $A_{1} R, A M P A$, and kainate receptors are blocked pharmacologically. $A$, Mossy fiber synaptic transmission is highly sensitive to activation of $A_{1} R s$. Application of the specific $A_{1} R$ agonist (PA (800 nm; large white bar) potently depresses fEPSPs. This depression is completely reversed by the $A_{1} R$ antagonist DPCPX (black bar). Note that full steady state of (PA perfusion was not achieved. $\boldsymbol{B}$, Time course ( $n=$ 4) and example traces of mossy fiber fEPSPs recorded in $A_{7} R^{-/-}$mice. Frequency facilitation is virtually identical to wild-type mice. Calibration: $0.1 \mathrm{mV}, 2 \mathrm{~ms}$. C, Schaffer collateral fEPSPs were recorded in the CA1 region of the same slices ( 3 of 4 ) used to test mossy fiber frequency facilitation to verify the phenotype of the mice. As expected, the $A_{1} R$ agonist (PA ( $800 \mathrm{~nm}$ ) was without effect on synaptic transmission in $A_{1} R^{-1-}$ mice (average time course, $n=3$ ) but strongly reduced fEPSPs in wild-type mice (average time course, $n=3$ ). Note that DPCPX (1 $\mu \mathrm{m})$ increases fEPSPs slightly above baseline to a degree very similar to that seen for mossy fiber fEPSPs (see $A)$. Calibration for example traces: $0.2 \mathrm{mV}, 4 \mathrm{~ms}$. D , In the presence of DPCPX $(1 \mu \mathrm{m})$, NMDA receptors were pharmacologically isolated with CNQX (30 $\mu \mathrm{m})$ and bicuculline $(10 \mu \mathrm{M})$. Mossy fiber $\mathrm{EPSC}_{\mathrm{NMDA}} \mathrm{S}$ were recorded in CA3 pyramidal cells held at $+30 \mathrm{mV}$ in whole-cell voltage-clamp mode. The residual EPSC recorded under these conditions at $-70 \mathrm{mV}$ was $<10$ pA. In each cell $(n=4)$, frequency facilitation was elicited two times, as indicated by the asterisks. Example traces of mossy fiber EPSC $_{\text {NMDA }}$ are shown on the right. Calibration: $100 \mathrm{pA}$, $10 \mathrm{~ms}$. The magnitude of $1 \mathrm{~Hz}$ frequency facilitation is similar to that measured with fEPSPs and is not dependent on activation of AMPA, kainate, or $A_{1} R s$. $\boldsymbol{E}$, Data shown in $\boldsymbol{D}$ are replotted. In each cell, the two trials of frequency facilitation were normalized and averaged before the mean values were calculated across all cells. 
A
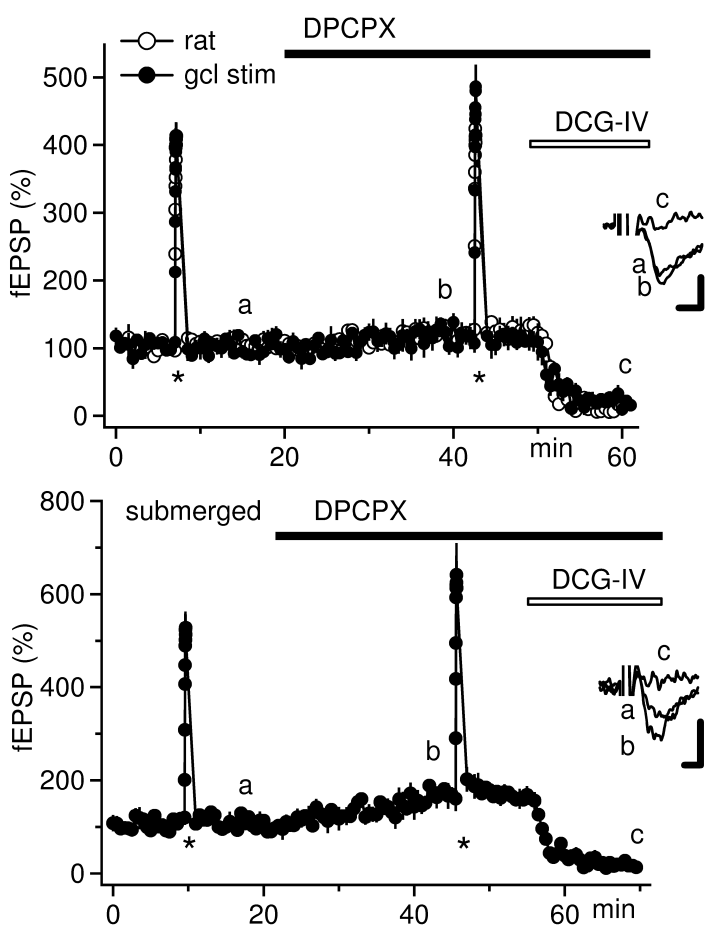

C

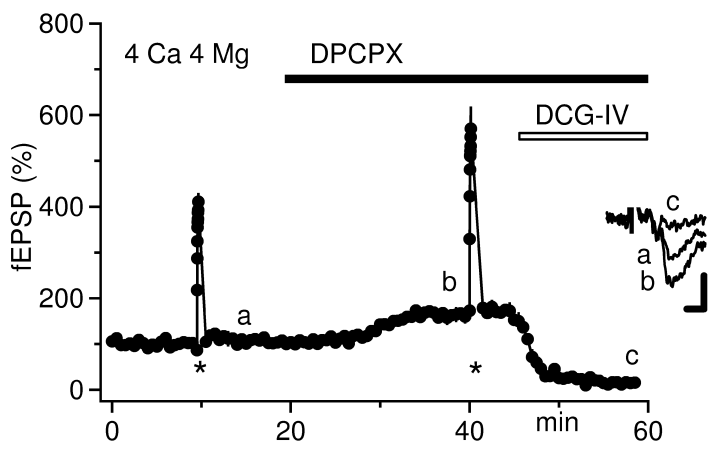

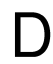

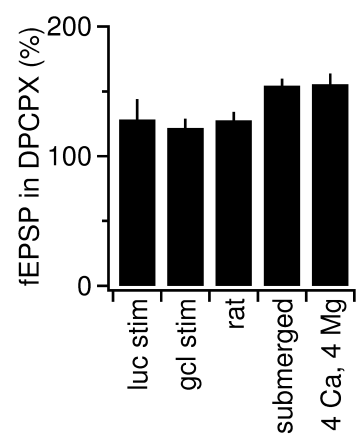

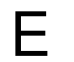

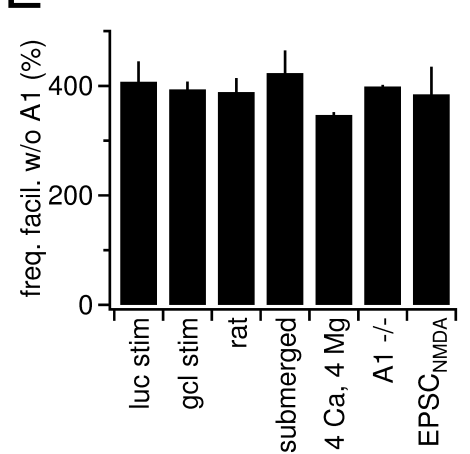

Figure 3. Enhancement of fEPSPs by DPCPX is increased in submerged recording chambers and in high concentrations of divalent cations. $\boldsymbol{A}$, Tonic inhibition of mossy fiber transmission by $A_{1} R s$ is similarly small in rats $(n=4)$ or when mossy fibers are stimulated close to the granule cell layer $(n=4)$. Calibration: $0.1 \mathrm{mV}, 1 \mathrm{~ms}$. B, Keeping slices in submerged recording chambers apparently elevates the level of ambient adenosine $(n=5)$. Potentiation by DPCPX is increased compared with interface chamber recordings (compare with $A$ ). Nevertheless, there is still a prominent frequency facilitation in the presence of DPCPX. Calibration: $50 \mu \mathrm{V}, 2 \mathrm{~ms}$. C, Synaptic transmission is more sensitive to blockade of $A_{1}$ Rs by DPCPX when slices are bathed in $4 \mathrm{~mm}$ $\mathrm{Ca}^{2+} / 4 \mathrm{~mm} \mathrm{Mg}^{2+}(n=4)$. However, even under this condition, frequency facilitation is not dependent on $A_{1} R$ activation. Asterisks indicate an increase in stimulation frequency to $1 \mathrm{~Hz}$. Calibration: $0.1 \mathrm{mV}, 2 \mathrm{~ms}$. D, Summary bar graph showing the increase in fEPSP amplitudes by $D P C P X$ under various recording conditions. $E$, Summary of the values of frequency facilitation (frea. facil.) obtained in the absence of $A_{1} R$ function. luc, Stratum lucidum; glc, granule cell layer; stim, stimulation. cording chamber (Fig. 3B), and perfusion of ACSF containing elevated divalent cation concentrations $\left(4 \mathrm{mM} \mathrm{Ca}^{2+}\right.$ and $4 \mathrm{~mm}$ $\mathrm{Mg}^{2+}$ ) (Fig. 3C). In general, under all conditions, the increase in fEPSP amplitudes by DPCPX was small (Fig. 3D). However, it should be noted that placing slices in a submerged chamber and elevating the divalent cation concentrations yielded a larger DPCPX effect (increase by 55\%) when compared with interface chamber recordings in mice or in rats (increase by $\sim 25 \%$ ) (Fig. $3 D$ ). Figure $3 E$ summarizes the values of $1 \mathrm{~Hz}$ frequency facilitation obtained in the absence of $\mathrm{A}_{1} \mathrm{R}$ function. Using a variety of methods, frequency facilitation ranged $\sim 400 \%$ but was slightly reduced in high divalent cation solution $(347 \pm 6 \%$; $n=4)$.

\section{Discussion}

In contrast to a previous proposal (Moore at al., 2003), we find that mossy fiber synaptic plasticity is not dependent on ambient adenosine and that the tonic inhibition of transmitter release mediated by adenosine is mild and comparable with that seen at other hippocampal synapses.

Our results clearly demonstrate that basal transmitter release at mossy fiber terminals is only weakly depressed by ambient adenosine. Removing the inhibitory action of adenosine with a high concentration of DPCPX $\left[1 \mu \mathrm{M} ; K_{\mathrm{D}}\right.$ at $\mathrm{A}_{1} \mathrm{Rs} \sim 1-3 \mathrm{nM}$ (Lohse et al. (1987)] increased mossy fiber fEPSPs by only $20-30 \%$. This amount of augmentation is in good agreement with a number of previous studies and our own observations (Fig. 2C) at the hippocampal Schaffer collateral-CA1 synapse (Dunwiddie and Diao, 1994; Brundege and Dunwiddie, 1996; de Mendonca et al., 1997; Latini et al., 1999; Bon and Garthwaite, 2002) but is much less than reported by Moore et al. (2003), who found a fivefold increase in mossy fiber fEPSPs during perfusion of DPCPX.

It is unlikely that this difference is attributable to a different adenosine sensitivity of mossy fiber terminals in our study compared with the preparation of Moore et al. (2003). In both studies, adenosine receptor agonists strongly inhibited mossy fiber synaptic transmission to a similar extent (reduced to $27 \%$ from a baseline of $118 \%$ ). This inhibition is mediated by the $A_{1} R$, as evidenced by the effectiveness of the specific $A_{1} R$ agonists CPA and 2-chloro- $N^{6}$-cyclopentyladenosine, by the effectiveness of the $\mathrm{A}_{1} \mathrm{R}$ antagonist DPCPX, and by the DPCPX insensitivity of fEPSPs in $A_{1} R^{-/-}$mice (Moore et al., 2003; this study). This inhibitory $A_{1} R$ is localized on mossy fiber terminals and depresses glutamate release via inhibition of presynaptic $\mathrm{Ca}^{2+}$ channels (Rivkees et al., 1995; Kamiya et al., 2002). The most straightforward explanation for the difference between our data and the experiments presented by Moore et al. (2003) is a higher concentration of extracellular adenosine in their preparation.

What could be the reason for the excessive level of extracellular adenosine in slices used by Moore et al. (2003)? Adenosine reaches the extracellular space principally in two different ways (Dunwiddie and Masino, 2001; Latini and Pedata, 2001): by catabolism of extracellular adenine nucleotides by ectonucleotidases (Zimmermann, 2000) or by release of intracellular adenosine through nucleoside transporters. Metabolic stress, such as hypoxia, can lead to an enormous elevation of the extracellular adenosine level, which nearly completely depresses synaptic transmission in hippocampal slices (Dale et al., 2000; Frenguelli et al., 2003). When compared with interface chambers, submerged recording chambers are less optimal for oxygenation of the tissue because of a limited transfer rate of oxygen through the perfusate (Tsacopoulos et al., 1981; Bingmann and Kolde, 1982). For this reason, elevated levels of ambient adenosine are more likely to occur in submerged slices. This idea is supported by our 
finding that the DPCPX effect is indeed significantly larger when we placed our slices in this type of chamber (Fig. 3B). Additionally, our findings indicate that the elevated divalent cation concentration used by Moore et al. (2003) renders synaptic transmission more sensitive to $A_{1}$ antagonism (Fig. $3 C$ ). Together, it appears likely that the high concentration of extracellular adenosine observed in the study by Moore et al. (2003) partially is a result of their recording conditions. However, there still is a dramatic difference in DPCPX effect when compared between our submerged chamber and high $\mathrm{Ca}^{2+} / \mathrm{Mg}^{2+}$ recordings (each increases to $\sim 155 \%$ ) and their results (increase to $\sim 500 \%$ ). The origin of this difference is unclear at present.

Another important result of our study is that the strong synaptic potentiation characteristic of mossy fiber transmission is not dependent on a permanent decrease of release probability by adenosine (as suggested by Moore et al., 2003). The magnitude of paired-pulse facilitation, frequency facilitation, and posttetanic potentiation measured in this study under control conditions compares very well to values published by other groups (Regehr et al., 1994; Salin et al., 1996; Toth et al., 2000; Castillo et al., 2002) and was unchanged when $A_{1}$ Rs were fully antagonized or genetically deleted. Thus, our results demonstrate that basal release probability at mossy fiber synapses is low enough to express this characteristic potentiation without the action of ambient adenosine. This is in striking contrast to Moore et al. (2003), who found that activation of $A_{1} R s$ is essential for the characteristic mossy fiber plasticity. A higher level of ambient adenosine fails to explain their finding that mossy fiber synaptic plasticity is indistinguishable from that of other hippocampal synapses in the absence of $A_{1} R$ activation. If the only difference between our study and their study were the ambient adenosine concentration, then in the presence of DPCPX as well as in $\mathrm{A}_{1}$ knock-out mice, we should measure the same degree of potentiation. In contrast, under those conditions, a much lower potentiation of transmission was observed by Moore et al. (2003): this study versus Moore et al. (2003), frequency facilitation, $\sim 400 \%$ versus $\sim 180 \%$; and posttetanic potentiation, $\sim 520 \%$ versus $\sim 280 \%$. This difference is apparently not attributable to elevated extracellular $\mathrm{Ca}^{2+}$ concentration used by Moore et al. (2003) ( $4 \mathrm{mM} \mathrm{Ca}^{2+}$ vs $2.5 \mathrm{~mm}$ in our study) because we observed only a slightly diminished frequency facilitation under that condition (Fig. 3E). A possible explanation could be that, without $\mathrm{A}_{1}$ activity, the basal release probability was higher in their study such that only a small additional potentiation could be achieved. The abovementioned putative hypoxia of slices in a submerged chamber or during preparation perhaps could have increased release probability. It has been demonstrated that glutamate release can be persistently increased in hippocampal slices after even a brief episode of severe hypoxia (Hsu and Huang, 1997; Ouanonou et al., 1999).

Together, our results clearly indicate that basal transmitter release at mossy fiber synapses is under mild control of ambient adenosine and that mossy fiber synaptic plasticity is not brought about by an inhibitory tone of $A_{1}$ Rs.

\section{References}

Bingmann D, Kolde G (1982) PO2-profiles in hippocampal slices of the guinea pig. Exp Brain Res 48:89-96.

Blatow M, Caputi A, Burnashev N, Monyer H, Rozov A (2003) $\mathrm{Ca}^{2+}$ buffer saturation underlies paired pulse facilitation in calbindin-D28kcontaining terminals. Neuron 38:79-88.
Bon CL, Garthwaite J (2002) Adenosine acting on Al receptors protects NO-triggered rebound potentiation and LTP in rat hippocampal slices. J Neurophysiol 87:1781-1789.

Brundege JM, Dunwiddie TV (1996) Modulation of excitatory synaptic transmission by adenosine released from single hippocampal pyramidal neurons. J Neurosci 16:5603-5612.

Castillo PE, Schoch S, Schmitz F, Sudhof TC, Malenka RC (2002) RIMlalpha is required for presynaptic long-term potentiation. Nature 415:327-330.

Contractor A, Swanson G, Heinemann SF (2001) Kainate receptors are involved in short- and long-term plasticity at mossy fiber synapses in the hippocampus. Neuron 29:209-216.

Dale N, Pearson T, Frenguelli BG (2000) Direct measurement of adenosine release during hypoxia in the CA1 region of the rat hippocampal slice. J Physiol (Lond) 526:143-155.

de Mendonca A, Almeida T, Bashir ZI, Ribeiro JA (1997) Endogenous adenosine attenuates long-term depression and depotentiation in the CA1 region of the rat hippocampus. Neuropharmacology 36:161-167.

Dietrich D, Kirschstein T, Kukley M, Pereverzev A, von der BC, Schneider T, Beck H (2003) Functional specialization of presynaptic Cav2.3 $\mathrm{Ca}^{2+}$ channels. Neuron 39:483-496.

Dunwiddie TV, Diao L (1994) Extracellular adenosine concentrations in hippocampal brain slices and the tonic inhibitory modulation of evoked excitatory responses. J Pharmacol Exp Ther 268:537-545.

Dunwiddie TV, Masino SA (2001) The role and regulation of adenosine in the central nervous system. Annu Rev Neurosci 24:31-55.

Frenguelli BG, Llaudet E, Dale N (2003) High-resolution real-time recording with microelectrode biosensors reveals novel aspects of adenosine release during hypoxia in rat hippocampal slices. J Neurochem 86:1506-1515.

Geiger JR, Jonas P (2000) Dynamic control of presynaptic $\mathrm{Ca}^{2+}$ inflow by fast-inactivating $\mathrm{K}^{+}$channels in hippocampal mossy fiber boutons. Neuron 28:927-939.

Hallermann S, Pawlu C, Jonas P, Heckmann M (2003) A large pool of releasable vesicles in a cortical glutamatergic synapse. Proc Natl Acad Sci USA 100:8975-8980.

Hsu KS, Huang CC (1997) Characterization of the anoxia-induced longterm synaptic potentiation in area CA1 of the rat hippocampus. Br J Pharmacol 122:671-681.

Johansson B, Halldner L, Dunwiddie TV, Masino SA, Poelchen W, Gimenez-Llort L, Escorihuela RM, Fernandez-Teruel A, Wiesenfeld-Hallin Z, Xu XJ, Hardemark A, Betsholtz C, Herlenius E, Fredholm BB (2001) Hyperalgesia, anxiety, and decreased hypoxic neuroprotection in mice lacking the adenosine A1 receptor. Proc Natl Acad Sci USA 98:9407-9412.

Kamiya H, Shinozaki H, Yamamoto C (1996) Activation of metabotropic glutamate receptor type $2 / 3$ suppresses transmission at rat hippocampal mossy fibre synapses. J Physiol (Lond) 493:447-455.

Kamiya H, Ozawa S, Manabe T (2002) Kainate receptor-dependent shortterm plasticity of presynaptic $\mathrm{Ca}^{2+}$ influx at the hippocampal mossy fiber synapses. J Neurosci 22:9237-9243.

Latini S, Pedata F (2001) Adenosine in the central nervous system: release mechanisms and extracellular concentrations. J Neurochem 79:463-484.

Latini S, Bordoni F, Pedata F, Corradetti R (1999) Extracellular adenosine concentrations during in vitro ischaemia in rat hippocampal slices. $\mathrm{Br} \mathrm{J}$ Pharmacol 127:729-739.

Lauri SE, Bortolotto ZA, Nistico R, Bleakman D, Ornstein PL, Lodge D, Isaac JT, Collingridge GL (2003) A role for $\mathrm{Ca}^{2+}$ stores in kainate receptordependent synaptic facilitation and LTP at mossy fiber synapses in the hippocampus. Neuron 39:327-341.

Lohse MJ, Klotz KN, Lindenborn-Fotinos J, Reddington M, Schwabe U, Olsson RA (1987) 8-Cyclopentyl-1,3-dipropylxanthine (DPCPX)—a selective high affinity antagonist radioligand for $\mathrm{Al}$ adenosine receptors. Naunyn Schmiedebergs Arch Pharmacol 336:204-210.

Moore KA, Nicoll RA, Schmitz D (2003) Adenosine gates synaptic plasticity at hippocampal mossy fiber synapses. Proc Natl Acad Sci USA 100:14397-14402.

Ouanonou A, Zhang Y, Zhang L (1999) Changes in the calcium dependence of glutamate transmission in the hippocampal CA1 region after brief hypoxia-hypoglycemia. J Neurophysiol 82:1147-1155.

Regehr WG, Delaney KR, Tank DW (1994) The role of presynaptic calcium 
in short-term enhancement at the hippocampal mossy fiber synapse. J Neurosci 14:523-537.

Rivkees SA, Price SL, Zhou FC (1995) Immunohistochemical detection of A1 adenosine receptors in rat brain with emphasis on localization in the hippocampal formation, cerebral cortex, cerebellum, and basal ganglia. Brain Res 677:193-203.

Salin PA, Scanziani M, Malenka RC, Nicoll RA (1996) Distinct short-term plasticity at two excitatory synapses in the hippocampus. Proc Natl Acad Sci USA 93:13304-13309.

Schmitz D, Mellor J, Nicoll RA (2001) Presynaptic kainate receptor mediation of frequency facilitation at hippocampal mossy fiber synapses. Science 291:1972-1976.
Toth K, Suares G, Lawrence JJ, Philips-Tansey E, McBain CJ (2000) Differential mechanisms of transmission at three types of mossy fiber synapse. J Neurosci 20:8279-8289.

Tsacopoulos M, Poitry S, Borsellino A (1981) Diffusion and consumption of oxygen in the superfused retina of the drone (Apis mellifera) in darkness. J Gen Physiol 77:601-628.

Urban NN, Henze DA, Barrionuevo G (2001) Revisiting the role of the hippocampal mossy fiber synapse. Hippocampus 11:408-417.

Zimmermann H (2000) Extracellular metabolism of ATP and other nucleotides. Naunyn Schmiedebergs Arch Pharmacol 362:299-309.

Zucker RS, Regehr WG (2002) Short-term synaptic plasticity. Annu Rev Physiol 64:355-405. 